\title{
Reflection-in-action: Measuring 'context' in medical interpreting
}

\author{
Robyn K. Dean \\ Rochester Institute of Technology \\ Robyn.Dean@rit.edu \\ https://orcid.org/0000-0002-4611-0139
}

\begin{abstract}
Community interpreting scholarship has solidly established the importance of appreciating the nuances of context to effective interpreting practice (Angelelli, 2004; Wadensjö, 1998). Several frameworks for identifying and articulating the way context affects interpreting work have been articulated (Dean \& Pollard, 2011). What is less well documented is the way interpreters learn to develop an understanding of context and how that subsequently informs their practice. This article describes the development and implementation of a tool to assess interpreters' facility in identifying and articulating context - specifically in healthcare settings. The activities and the assessment tool are grounded in the educational theories of Donald Schön and his foregrounding of the intuitive practice abilities of professionals. The resulting assessment tool was refined through its use in postgraduate courses in healthcare interpreting, where various aspects of the healthcare context were explained using videos of provider-patient interactions. Through reflective practice activities, students analysed their practical knowledge and skills and improved their context-based insight. Currently designed for signed language interpreters in medical settings based in the United States, this multicomponent assessment tool can be adapted to various contexts in community interpreting.
\end{abstract}

Keywords: medical interpreting, healthcare interpreting, ethical sensitivity, ethics, reflective practices, interpreter education, interpreter training

\section{Introduction}

The word "practical" in the title of a university course conveys to potential students a curriculum design focused on applied knowledge and skills. Designing a course that promises to advance practical knowledge and skills in situ means putting students in proximity to the actual act of doing. Those activities of proximity are often graduated, designed to move the student increasingly closer to the actual act. In the field of healthcare, for example, gaining experience that is practical, or clinical, means moving providers closer to patient care. Clinical skills are those related to the observation or treatment of actual patients or, as the original

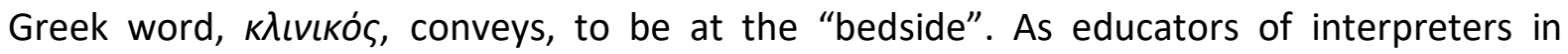
healthcare settings, we similarly focus on improving and assessing the practical skills of healthcare interpreters. 
For decades, medical school educators have been concerned with the clinical skills of medical providers, that is, the effective application of knowledge and skills at the bedside (Barrows, 1994). Towards that end, medical school curricula have come to centre on the patient. From the starting point of the patient's chief complaint, educational activities are then expandedthe necessary knowledge of anatomy and physiology, the necessary tests and assessments, and so on. These designs are similarly graduated, starting with written case scenarios, moving to live simulations with hypothetical patients (e.g., trained actors a.k.a. simulated patients), then ultimately ending in supervised practice with actual patients.

The curricular reforms made in medical education have been a major influence (both the literature and the materials) on the development, the design and the course materials in the National Technical Institute for the Deaf or NTID'si online postgraduate degree programme for healthcare interpreters. This is reflected in two foundational courses: Healthcare Practical Interpreting I \& II. In these courses we aimed to accomplish the promise of practicality by increasing the student's proximity to the bedside.

While the proverbial bedside might capture the practice setting for those who assess and treat patients, healthcare interpreters need an apt parallel term that is modified to be more inclusive of patients, providers and the setting. As bedside is to the provider, so is context to the community interpreter. To a provider, the patient's complaint or problem is the fulcrum around which all investigations and ultimately treatment revolve. To the community interpreter, it is the context (and the evolving context) that impels all translation ${ }^{\mathrm{ii}}$ and behavioural decisions. In other words, no practitioner, including community interpreters, works in the abstract but rather in the "messy indeterminate situations" of professional practice (Schön, 1987, p. 4).

In a recent publication (Dean, 2018), I outlined the use of course materials that centred on teaching healthcare interpreting by moving students increasingly closer to the healthcare context (from case scenarios to videotaped interactions and eventually to shadowing providers). While a summary of one of those teaching tools (the videotaped medical interactions) is provided here, the main contribution of this article is to illustrate the development and use of a tool for assessing a student's knowledge of the context of healthcare interpreting. This multi-component assessment evolved as a result of its use with several cohorts of American Sign Language-English (ASL-ENG) interpreters enrolled in NTID's postgraduate degree programme. While the term "students" is used here, it is important to note that all postgraduates are nationally qualified practising interpreters, many of them with substantial experience in healthcare interpreting. As a reminder of this status, every now and then the term "student/practitioner" is used in this article.

\section{Knowing and knowledge of context}

Interpreters who work in community settings - medical, educational and legal, for example base their decisions on salient factors in each setting (Angelelli, 2004; Napier, 2004; Pöchhacker, 2004; Roy, 2000; Wadensjö, 1998). Researchers have observed these contextdriven behaviours in situ, showing that context matters in interpreters' work (Davidson, 2001; Hsieh, 2006, 2007). Salient contextual factors stem from the setting-domain in which the interpreting is occurring, both from the participants (e.g., emotional and psychological states, 
interpersonal dynamics, expectations, etc.) and even from the interpreters themselves (Corsellis, 2008; Dean \& Pollard, 2011; Hale, 2007).

While scholars have identified the importance of context and have even, in some cases, proposed frameworks for identifying and articulating context (Dean \& Pollard, 2011), most practising interpreters would probably understand the context as practitioners more experientially than cognitively (Schön, 1983; Smith, 2014). In other words, asking the average interpreter to think back to their last work assignment to identify the salient contextual factors might not prove fruitful. Interpreters are more likely to be able to identify contextual factors indirectly, that is, by highlighting what they did and then asking them why they took particular actions or decided on a particular interpretation or translation (Dean \& Pollard, 2009; Smith, 2014).

This phenomenon is not unique to community interpreters. Practical knowledge or knowledge applied in a clinical setting is often attained and expressed through tacit processes (Argyris \& Schön, 1974; Gladwell, 2005; Kahneman, 2011; Schön, 1983). When competent practitioners work, they reveal what they know even if their verbal skills are insufficient to explain what they know (Argyris \& Schön, 1974; Farrell, 2012; Schön, 1983). Schön referred to this as knowing-in-action, proposing further that regularly engaging in structured reflective practices advances instinctual knowing-in-action to the conscious awareness level that it is then referred to as knowledge-in-action.

Reflecting on or the analyses of one's actions as a means of learning and development was introduced by John Dewey in the 1920s. The term reflective practice was later coined and disseminated by Donald Schön in the 1980s with the publication of his book, The Reflective Practitioner. The rigour of reflection and its value to the professional development of practitioners is still discussed today, along with growing bodies of research and theoretical approaches (Farrell, 2012; Kinsella, 2010), including those on the value of reflective practices in medical education (see, e.g., Bindels et al., 2018).

Through the use of structured reflection, a practitioner becomes consciously aware of what they know and how that knowledge informs their practice. As the theory goes, with conscious awareness, a practitioner is able learn from, correct and improve their practice (Argyris \& Schön, 1974; Schön, 1983). Argyris and Schön (1974) summarised it this way:

A central part of the task of professional education ... [is] to formulate "what we already know", that is, to capture in explicit form the insights, values, and strategies of action that competent practitioners bring to situations they encounter in practice. The challenge for professional education was to effect a new kind of marriage of applied science, on the one hand, and knowing and reflection-in-action, on the other. (p. 47)

In essence, the authors are proposing that professional education is most effective when it combines practitioners' existing knowledge of practice with the relevant applied sciences (e.g., frameworks and theories) and the rigour of reflection. For Argyris and Schön, the rigour of reflection is accomplished vis-à-vis the effective application of relevant theories and frameworks (i.e., applied sciences). 
To reflect on one's action (i.e., one's practice) is to do so retrospectively - thinking through and critiquing what happened. The ability to reflect in action - metacognitively aware of what is happening in the moment - emerges from the regular practice of reflecting on action. It is through this iterative process that knowing-in-action becomes knowledge-in-action - the conscious awareness of what is known, how it is known and how that knowledge informs one's practice. Practitioners often fail to advance from knowing-in-action to knowledge-inaction. That is, they might reveal their unformulated knowledge clinically (e.g., at the bedside), and perhaps even competently so; but most struggle to explain what they know or justify the way their practice decisions reflect that knowing (Argyris \& Schön, 1974; Farrell, 2012; Gladwell, 2005; Schön, 1983).

Additional concern for professional educators arises when they move from working as a practitioner to being an educator armed with only the knowing and not the knowledge. Perhaps this explains the frequent use of the phrase "it depends..." when interpreter educators are asked to explain how they might translate a particular concept or how they might act in a particular situation (Dean \& Pollard, 2011; Winston, 2005). What follows on from it depends is a series of if/then statements. For example, "If the patient had recently immigrated, then I might ask the provider to explain the process for booking a CT scan. If the patient were familiar with the country's healthcare system, then I would just interpret directly that a CT scan is needed" (more examples provided in Dean \& Pollard, 2013, p. 100).

Here, the interpreter's knowing is embedded in their practice. If this were an explanation to a student or a new professional, then the embedded-in-examples explanation might not enable optimal learning. Moving from knowing to knowledge per Schön means in part explaining the underlying theoretical principle that is formulating these if/then statements. Without such constructs of the applied sciences, it is unlikely that a student or a new professional could generalise their practical wisdom or phronesis to other contexts.

Whether or not contextual factors in interpreting were effectively learned in ASL-ENG interpreting classrooms was the focus of a study 20 years ago (Dean \& Pollard, 2001). The study found that most respondents who graduated from an interpreter education programme came to learn about the importance and function of the interpreting context - at least for the most part - after they had graduated. The respondents claimed that they had gained crucial practice skills on the job while interpreting for individuals (Dean \& Pollard, 2001). According to Dean and Pollard (2001), however, "[a]llowing these critical interpreter competencies to develop haphazardly, on the job without supervision ... is an error of oversight" (p. 9).

\section{Effective practice and ethical sensitivity}

If an understanding of the importance and function of the interpreting context is left to develop haphazardly on the job and is left to function primarily at the tacit level, then educators and practitioners are both disadvantaged: educators in their aim to pass along practical knowledge and skills and practitioners in reflecting on and assessing work performance. When a practitioner fails to recognise, consider and respond to the elements of the practice setting, then there is a gap in their clinical skills or a failure of ethical sensitivity (Rest, 1984). Rest's ethical sensitivity (1984) refers to the ability to apprehend accurately the 
complexities of a situation and how one's actions affect the situation and the people in it. To be explicit, Rest is elevating being effective as a practitioner to being an ethical practitioner. Ethicists have long referred to the fittingness of actions as an ethical determinant (Howard, 2018) - that is, actions or decisions must fit the situation or the context. Bebeau (2002) broadened her definition of professional practice by claiming that "[p]rofessional practice is predominantly a moral enterprise" (p. 271). Accordingly, failures of ethical sensitivity lead to ineffective professional practices (see also Dean, 2014; Hill, 2004).

While context matters in interpreting work, interpreters might struggle to identify and express contextual factors in sophisticated ways. As noted above, this could be due to unformulated knowing-in-action or it might be a failure to acknowledge and understand the contextual factors - a failure of ethical sensitivity.

Knowing-in-action can become knowledge-in-action only with the introduction of relevant theories and frameworks and the rigour of structured reflective practices (Farrell, 2012; Kinsella, 2010). Only when the interpreting context is elevated to knowledge-in-action can it be assessed for completeness and relative accuracy, which is the aim of advancing ethical sensitivity. Developing ethical sensitivity should therefore be one of the aims of professional education (Dean, 2015, 2018; Hill, 2004; Rest, 1984). In interpreter education this in part means explicitly teaching the components of context - both the theoretical and the practical.

\section{Teaching context and ethical sensitivity}

Saying that context matters in community interpreting is one thing but operationalising that context to practical and manipulatable elements (i.e., theory-making) is a crucial next step: being able to name and identify something allows it to be studied, understood and manipulated. Classifying, arranging and organising complex phenomena is the work of taxonomies - helping the human brain to break down and manage information. Having relevant theories or frameworks in place for professional practice helps practitioners to assimilate and retrieve new data. They are also vital to framing research and directing professional education design and materials.

Dean and Pollard (2011) have proposed in their demand control schema that context in community interpreting emerges in the communication event via four sources: environmental, interpersonal, paralinguistic and intrapersonal. Brief definitions of each category follow:

- Environmental: those contextual elements that are specific to a setting (e.g., the goal of the setting, the personnel or clientele present, the unique terminology of that setting and the physical surroundings).

- Interpersonal: those contextual elements which are specific to the interactions that occur between the service users, including the interpreter (e.g., cultural factors, communication goals of the encounter, moods/emotional tone).

- Paralinguistic: those contextual elements that are specific to the quality of the expressive skills of the deaf and hearing service users (e.g., pace, volume, accents, visual or auditory impediments to perception). 
- Intrapersonal: those contextual elements that are specific to the internal experiences of the interpreter (e.g., thoughts, feelings, physical states).

Identifying that these factors matter is sufficient to creating theoretical frameworks but their clinical application, or the way they play out in practice, requires an exploration into how and why they matter. If context is so crucial in community interpreting - driving such decisions as how to act and how best to interpret utterances - then acquiring an understanding of the context should not be a function of happenstance. Teaching context in community interpreting cannot be left to on-the-job acquisition and mere implicit processes; it must be systematically and deliberately taught.

Since all educators of service professionals are arguably striving to provide opportunities for the practical application of classroom knowledge to the practice setting, and since community interpreters are frequently paired with these very same service professionals (i.e., interpreting for nurses, teachers, etc. in public service settings), then it stands to reason that their efforts and their materials should be adopted and modified for use in community interpreter education (Dean, 2018; Dean \& Pollard, 2009, 2012; Major et al., 2012). It was indeed one such collaboration with a local medical school that provided me with more than one hundred videotaped samples of patient-provider diagnostic discourse from the school's standardised patient programme.

\subsection{Practical healthcare interpreting courses}

The course design for the two practical courses follows a graduated approach in the context of healthcare. The initial step is to start with interpreting cases (using actual interpreted medical events, not constructed scenarios) which are analysed through the lens of relevant theories and constructs (Dean, 2018; Dean \& Pollard, 2012). This is reflection-on-action, retrospectively analysing the cases of either the students/practitioners or collected sample cases provided by medical interpreters. The final step is observations of healthcare contexts where interpreters shadow providers during appointments with real patients, a practice known as observation-supervision (Dean \& Pollard, 2009, 2012). The middle step, the use of the standardised patient programme (SPP) videos, is a step up from the static nature of a case but a step down from the dynamic nature of an in-person observation. It is this middle step which has resulted in an assessment tool for healthcare interpreting contexts that is outlined in the next section.

The use of standardised patients in medical schools is popular worldwide. Standardised patient programmes (SPP) are an effective tool that enable medical students to practise their clinical skills on would-be patients (actors with assigned illnesses). Through a local teaching hospital's standardised patient programme, I was given access to more than one hundred videos of diagnostic interviews. Provider and patient in this case are medical students and actors, both of whom are speaking the same language (English). The actors do not follow a script, so their speech is spontaneous and their interactions relatively authentic (Major et al., 2012). The actor-patients are instructed to provide (mostly when asked) a list of symptoms and in some cases the details of their back story. All SPP videos are labelled and identified by the patient's presenting complaint. In medicine, the presenting or chief complaint drives the differential diagnostic interview (see Dean, 2018). These 20-minute videos parallel a typical 
initial diagnostic interview. A description of one of these SPP videos is provided below (see also Dean, 2018).

When these SPP videos and their use are introduced to students, each video is initially accompanied by a worksheet - a series of questions designed to place the students in the interaction as if they were interpreting. The worksheet questions further link the content of the video to some practical application in interpreting. Each video and worksheet (which are completed by individual students), is followed by research and online discussions. These discussions result in students collectively reflecting on their existing knowledge or practice and how any new knowledge as a result of the video might now inform their current practice (Dean, 2018).iii

Near to the end of the course in practical interpreting, the students/practitioners have watched more than ten hours of provider-patient interactions and engaged in many more hours of application (i.e., worksheets) and reflection (i.e., online discussions). These worksheets are still an example of Schön's reflection-on-action, even though that action is hypothetical. That is, in answering questions about "how might you translate ..." or "how might you deal with ...", the students offer possible decisions that they could or might take in those instances.

Increasing the cognitive challenge from reflection-on-action to reflection-in-action comes with the culminating activity in the final weeks of the course. This concluding activity is intended to move the student/practitioner from being retrospective, as they were in reflecting on their and others' past actions (i.e., case examples) and on their own proposed action (i.e., worksheets and online discussions), to being reflective in present action. Granted, SPP videos provide a simulated action only - the student/practitioner is placed in a parallel experience designed to create a type of cognitive action. That is, in this reflective activity, these final provider-patient videos serve to simulate an interpreted interaction cognitively and, at least theoretically, by doing so activate the student's/practitioner's tacit practice knowledge.

\section{Measuring context and ethical sensitivity}

The reflection-in-action activity along with the three SPP videos are the means of measuring ethical sensitivity gains. No longer guided by the in-hand worksheet, students/practitioners are asked simply to watch the new provider-patient interview and at the moments they are compelled to, pause the video and comment on the discourse, interaction or other components of the interpreting context.

There is no permitted rehearsal, since the students/practitioners are given three opportunities with separate videos to incorporate the feedback and improve their next performance. Basically, this assignment is done cold - they are not provided with any rubric on how they are to be assessed. It is designed this way for a couple of reasons. First, the SPP video worksheets and online discussions from the first half of the course should already have primed their thinking about how context is explained and how practice decisions are explored. Second, assigning a rubric imposes teaching-centred limitations. With rubrics in hand, students tend to see only what they are asked to look for, and that runs counter to 
Schön's directive: competent practitioners demonstrate what they know through their knowing-in-action (see also Farrell, 2012).

The preparation that the students/practitioners have is similar to what they might be given in advance of an actual interpreting assignment. They are provided with the presenting complaint and descriptive information about the provider and the patient (e.g., age, ethnicity). Akin to practice, too, they are permitted to conduct any research, having been given these initial facts from the (simulated interpreting) context.

All of the SPP reflective activities are completed using video-streaming and screen-capture technologies. Because of the confidential nature of the content, the SPP videos cannot be downloaded but are instead streamed from the university's streaming platform. The students/practitioners record themselves watching and commenting on the interaction using the screen-capture software (several free versions are available online) and then submit that recording for assessment.

The final video of the three SPP videos is shoulder pain. Given that it is their third iteration of this activity (with feedback after each completed submission), this should arguably represent their best work. What follows is a brief description of the content of this dialogue, which is needed in order to understand the students' commentary below. As a reminder, the "patient" is an actor who has been assigned a chief complaint and a brief back story. Any remaining details in response to the provider's questions are expected to be improvised.

The patient is female, in her late 40s, and is presenting with shoulder pain. The provider is male, in his early $30 \mathrm{~s}$, and a medical student who is an intern with the patient's physician. He explains that he is there to do the initial interview and physical examination before her regular physician attends to her.

The interview follows a typical diagnostic interview when the patient's presenting complaint is pain (assumed to be the result of an older injury). A pain evaluation and a physical examination are conducted. The physical examination that follows the evaluation takes about five minutes and includes tests of the patient's muscles, nerves, and range of motion test. The appointment ends with an explanation of what the provider thinks is going on, what he wants to rule out (i.e., differential diagnosis) and a treatment plan.

The shoulder pain video is rather typical of all the SPP videos in its protocol: interview, physical examination, differential diagnosis discussion and a proposed disposition or treatment plan. While this is the typical protocol in all the SPP videos, what is unique to each interview are the particular interpersonal aspects of the provider-patient interaction - the provider (medical student) and the patient (actor) - the particularities of their dialogue, their interactions and the dynamics between them, to name a few.

What follows below is a list of the 15 components of the healthcare context in my assessment of student performance, examples of student commentary from the shoulder pain video and, finally, a complete table of the 15-component assessment tool with a definition of each component. 
Dean, R. K. (2021). Reflection-in-action: Measuring 'context' in medical interpreting, Linguistica Antverpiensia, New Series: Themes in Translation Studies, 20, 248-266

According to the 15-component assessment tool for healthcare interpreting contexts, the student/practitioner: 
1. Identifies environmental demands

2. Identifies paralinguistic demands

3. Notes examples of translation challenges

4. Proposes translation suggestions

5. Notes possible thought world components of patient

6. Notes possible thought world components of provider

7. Identifies potential intrapersonal demands

8. Identifies the dynamics between patient and provider and/or interpreter

9. Notes decision junctures

10. Offers control options along the liberal to conservative spectrum

11. Notes how possible decisions might impact service users or the situation

12. Uses conjecture or prediction about patient/provider semantics or thought worlds:

13. Articulates content knowledge or the need for it regarding the interview 14. Identifies examples of providers' effective/ineffective practice techniques

15. Recognises aspects of the medical interview

Student commentary follows next: what they said when they opted to pause the shoulder pain video. The corresponding component is also noted below each comment:

Student A: $\quad$ The provider asked, "Does it feel like a muscle pain or does it feel like a pain inside your shoulder? So, the sense of pain 'inside the shoulder' versus 'muscle pain' - that may be a little bit difficult to convey or tease out. [Component \#3]

Student B: The provider just asked, "Does anything seem to make it better?" I would preface that question with examples, "Are you taking any medication, like Tylenol, or ibuprofen? Are you refraining from moving it or doing any stretches? Applying heat or ice? Is there anything you're doing to make it feel any better?" [Component \#4]

Student C: $\quad$ The patient recognizes that taking a medication like ibuprofen can take time to get better - that the pain won't go away with just a few or inconsistent dosing. This leads me to believe that she is a bit more knowledgeable about how to take care of some injuries and ailments. Not all patients understand that. [Component \#5]

Student D: Ilike his [the provider's] introduction; it's light and humorous. He's attempting to build rapport right away by recognizing her painful shoulder [and] purposely does not shake that hand. His concern for her is the very first thing he says. If I were interpreting their first-time meeting, this dynamic would be important. [Component \#8]

Student E: $\quad$ The provider is moving around as he is washing his hands and the patient is trying to follow him. If this patient were deaf, she would need to see both me and the doctor. I would need to decide whether to try to follow him around or 
Dean, R. K. (2021). Reflection-in-action: Measuring 'context' in medical interpreting, Linguistica

Antverpiensia, New Series: Themes in Translation Studies, 20, 248-266

to stay in one place, hoping he would get situated soon. [Component \#9]

All of these comments reflect aspects of the interpreting context in healthcare, even if they are basic elements (i.e., translation, placement). Represented here are concerns about complex utterances, suggestions for possible translations, an assessment of patient's relevant knowledge, commentary on patient-provider dynamics, and logistical concerns for sightline and interpreter placement.

In addition to the above, there are the comments informed by Dean and Pollard's dimensions of context: environmental, interpersonal, paralinguistic and intrapersonal (EIPI). Some of these overlap with Rest's ethical sensitivity:

Student F: $\quad$ The goal of this encounter is for the doctor to diagnose what is wrong and to figure out a treatment plan. The provider is male and a medical student and the patient is female in her 50s. Associated terminology based on the presenting complaint will likely reference the anatomy of the arm, the joints, the muscles surrounding the shoulder, possibly the biceps, triceps, and the movement of those joints and muscles.

[Component \#1]

Student G: Considering the arm and shoulder manipulations during the physical exam, I am imagining that a patient who uses sign language might struggle when trying to move a part of their body that's in pain; this will impact their clarity. Perhaps they would communicate using their non-dominant side/hand or maybe they would keep signing with their dominant side but it would be physically limited.

[Component \#2]

Student $\mathrm{H}$ : The provider asks about her employment. Two reasons basically behind this. One is that the job could actually be a factor causing this pain. Another one might be that the job has nothing to do with causing the pain but going back to work would actually make the pain worse or exacerbate whatever her situation is. So, this is why he's asking about her employment situation.

[Component \#6]

Student I: $\quad$ One intrapersonal demand that would come up for me is when the patient mentions her stress and her concern for being the only woman on the loading dock at her work. She's probably heard this is a man's job and she can't cut it; maybe she has to work that much harder just to prove herself. Unfortunately, it is a reality for a lot of women who work in male-dominated environments; I can see myself being bothered and distracted by this.

[Component \#7] 
Student J: The provider is using the zero to ten pain scale. Some patients struggle to follow that. There are a few ways to deal with that confusion. First idea is to use the pain faces from the Wong-Baker scale. If they do not already have this scale in the office, I could pull one up on my smart phone. Or, I could interpret the question using words represented in the pain scale, such as, "Are you in a little bit of pain, a lot of pain, or moderate pain?" Then either I'd directly interpret the answer as is or choose a number on the zero to ten scale that reflected the patient's reply.

[Component \#10]

Student $K: \quad$ The sensory test that the provider is conducting as part of the physical exam is challenging for interpreters. The provider directs a patient to do something (e.g., "squeeze my fingers as tight as you can") and because of the lag imposed by the interpretation, there is a delayed response - and an even greater delay when the patient is not understanding (e.g., "push back against me"). It might be better if much of those are conveyed visually by the provider to the patient with the directive to just "do what I do".

[Component \#11]

These comments represent not only Dean and Pollard's categories of EIPI as the components for context but also their constructs associated with the intention and thinking of service users (i.e., thought worlds). In this instance, it is the intention behind the provider's question regarding the patient's employment that informs the comment from Student $\mathrm{H}$.

Rest (1984) and Dean and Pollard (2011) both emphasise the importance of consequences how an interpreter's decisions might affect service users. This is evident in the comment from Student K, which refers to the way in which the additional time required for a particular translation (i.e., the interpreter's decalage) can affect the timing of the give-and-take during the neurological examination.

Finally, below are sample comments regarding aspects of the context informed by the medical setting, the providers and the healthcare protocol:

Student L: Now it's coming to the point of the educational part of the interview. The provider is explaining that muscle and its role in the movement of the arm. He is now starting with the treatment plan. He has given a six-week window to increase the ibuprofen and to attend physical therapy; she is to return if this does not help. That's what I am seeing as part of the educational and the treatment plan components of the interview.

[Component \#15]

Student M: After the patient mentioned her car accident months prior, the provider asked, "did the airbags deploy?" when the patient mentioned her car accident. I wonder if he's going to follow up to ask about any potential head injuries; that's not really the focus of this appointment, but it is possible that he asks because it can be pretty traumatic when the airbags deploy.

[Component \#12] 
Student $\mathrm{H}$ : The use of the zero to ten pain scale is common. It's a very good technique because it puts a number to the pain; pain is not very concrete. Also, it is useful, because in follow-up visits they'll ask that question again, which lets the provider know if the pain is getting worse or it's getting better. It's a good way to document on all the different visits how the pain is doing.

[Component \#13]

Student N: I like how this provider is showing empathy for the patient and her situation by saying, "Wow, five weeks is a long time to be dealing with this." He is also leaning forward and taking his time and definitely using active listening skills [Component \#14]

In these examples, the students' commentary demonstrates their knowledge of a typical clinical interview and how providers commonly move between different elements (e.g., from questions about health history to an evaluation of pain); the implications of new data possibly requiring a series of rule-out questions (or follow-up tests and procedures); the use of tools to assess patients and, finally, the recognition of rapport-building behaviours and why they are important in healthcare provision.

\section{Assessing students' reflections on healthcare contexts}

The development of this multi-component assessment tool has been an iterative process. While about half of the context measures were derived from theories studied in the programme, the other half were derived from the recurring nature of a particular theme in student commentary. A new component would warrant differentiation from the broader context when a particular aspect of the context emerged consistently from the students'/practitioners' commentaries. Table 1 lists each component of context along with a brief definition.

Table 1: Multi-component assessment tool for healthcare interpreting context

\begin{tabular}{|l|l|}
\hline \multicolumn{1}{|c|}{ Component } & \multicolumn{1}{c|}{ Definition } \\
\hline Identifies environmental demands & $\begin{array}{l}\text { Aspects of the environmental demand category include } \\
\text { (a) physical surroundings, (b) terminology or } \\
\text { vocabulary, (c) personnel and clientele and (d) the goal } \\
\text { and values of the setting (Dean \& Pollard, 2011). }\end{array}$ \\
\hline Identifies paralinguistic demands & $\begin{array}{l}\text { Paralinguistic demands are the expressive qualities of } \\
\text { the patient and the provider that can compromise the } \\
\text { process of message transfer (Dean \& Pollard, 2011). }\end{array}$ \\
\hline $\begin{array}{l}\text { Notes examples of translation } \\
\text { challenges }\end{array}$ & $\begin{array}{l}\text { Translation challenges are utterances that are not } \\
\text { understood, confusing, or which might require the } \\
\text { strategy of explicitation. }\end{array}$ \\
\hline Proposes translation suggestions & $\begin{array}{l}\text { Sometimes this measure is connected to the above } \\
\text { translation challenges or sometimes interpreters just } \\
\text { comment on their standard approaches to common } \\
\text { questions. }\end{array}$ \\
\hline $\begin{array}{l}\text { Notes possible thought world } \\
\text { components of patient }\end{array}$ & $\begin{array}{l}\text { This measure of thought worlds (Namy, 1978) is } \\
\text { summarised by an interpreter's estimations of what }\end{array}$ \\
\hline
\end{tabular}


Dean, R. K. (2021). Reflection-in-action: Measuring 'context' in medical interpreting, Linguistica Antverpiensia, New Series: Themes in Translation Studies, 20, 248-266

\begin{tabular}{|c|c|}
\hline & $\begin{array}{l}\text { the patient is thinking, feeling, etc. relevant at any } \\
\text { given moment. }\end{array}$ \\
\hline $\begin{array}{l}\text { Notes possible thought world } \\
\text { components of provider }\end{array}$ & $\begin{array}{l}\text { Again, this is the interpreter's estimation of relevant } \\
\text { thoughts and feelings, but in this case for the provider. }\end{array}$ \\
\hline $\begin{array}{l}\text { Identifies potential intrapersonal } \\
\text { demands }\end{array}$ & $\begin{array}{l}\text { Intrapersonal demands refer to the relevant emotional, } \\
\text { psychological and physical experiences of the } \\
\text { interpreter (Dean \& Pollard, 2011). }\end{array}$ \\
\hline $\begin{array}{l}\text { Identifies dynamics between patient } \\
\text { and provider and/or interpreter }\end{array}$ & $\begin{array}{l}\text { Aspects of the interaction between patient and } \\
\text { provider that can be surmised from the events } \\
\text { depicted in the video or what might also be true if the } \\
\text { interpreter were present and included in those } \\
\text { interactions. }\end{array}$ \\
\hline Notes decision junctures & $\begin{array}{l}\text { When something is said or done that the interpreter } \\
\text { thinks would require action (and does not fit in to } \\
\text { another existing category), this is a type of decision } \\
\text { juncture. }\end{array}$ \\
\hline $\begin{array}{l}\text { Offers options along the liberal to } \\
\text { conservative spectrum }\end{array}$ & $\begin{array}{l}\text { Dean and Pollard (2005) define "ethical action" as } \\
\text { running along a continuum from conservative to } \\
\text { liberal, or from less action to more action. Taking some } \\
\text { action and taking no action at decision junctures are } \\
\text { two components of Rest's ethical sensitivity. }\end{array}$ \\
\hline $\begin{array}{l}\text { Notes how decisions might affect } \\
\text { service users or the situation }\end{array}$ & $\begin{array}{l}\text { This is the final part of Rest's ethical sensitivity - the } \\
\text { impact or consequences of a decision (Rest, 1984). }\end{array}$ \\
\hline $\begin{array}{l}\text { Uses conjecture or prediction about } \\
\text { patient/provider semantics or thought } \\
\text { worlds }\end{array}$ & $\begin{array}{l}\text { Part of being an effective interpreter is being able to } \\
\text { understand or predict accurately what might happen } \\
\text { next (Dean, 2018). With sufficient exposure, } \\
\text { interpreters begin to find aspects of the medical } \\
\text { interview and typical interactive components quite } \\
\text { predictable. }\end{array}$ \\
\hline $\begin{array}{l}\text { Articulates content knowledge or the } \\
\text { need for it regarding the interview }\end{array}$ & $\begin{array}{l}\text { It is not likely that interpreters can or will know } \\
\text { everything there is to know about anatomy, } \\
\text { physiology, symptoms, diseases, medications, } \\
\text { treatments, etc. But it is important for them to identify } \\
\text { when medical content knowledge is known or needs to } \\
\text { be known. }\end{array}$ \\
\hline $\begin{array}{l}\text { Identifies examples of providers' } \\
\text { effective/ineffective practice } \\
\text { techniques }\end{array}$ & $\begin{array}{l}\text { Effective communication and culturally appropriate } \\
\text { medicine are two hallmarks of evidence-based medical } \\
\text { practice, so effective medical practice and increased } \\
\text { effectiveness for the interpreting process often overlap } \\
\text { in practice. }\end{array}$ \\
\hline Recognises aspects of medical interview & $\begin{array}{l}\text { Medical interviews have different components: the } \\
\text { interview, pain evaluation, patient education, etc. } \\
\text { Again, the more interpreters are able to recognise } \\
\text { these, the more effective they will be (Dean, 2018). }\end{array}$ \\
\hline
\end{tabular}

As noted above, shoulder pain is the final video in the reflection-in-action activity which completes the course. Students/practitioners improve the frequency and sophistication of those components of context on which they offer their thoughts and reflections. Their first attempt at this activity is often limited - only readily commenting on the complexity of a 
particular utterance and the possible translation, issues of placement and their emotional reactions to the patient or the provider. Such reflections are indeed salient to this reflectionin-action activity, but my feedback on their first submission is aimed at expanding their identification of the healthcare context. As Argyris and Schön (1974) might frame it, in my feedback I am simply reminding them of what they already know. Their sophistication in formulating context and how that informs their practice has been demonstrated in worksheets, online discussions and examinations of their knowledge of the medical content. I also provide them with former students' examples that illustrate particular components. This is usually all it takes - their second and final submissions show a notable improvement in frequency and sophistication.

For shoulder pain, the final video, they receive a completed marking template with tick marks accounting for the frequency of each component noted and an example from their reflections. Over the past five years of their use, I have been collecting students' commentaries (anonymously, with their permission) and categorising comments during each minute of an interaction. For example, most interpreters pause the shoulder pain video at the first minute mark to comment on how the provider enters and how he immediately starts to wash his hands while trying to explain his role. The sink is placed behind the patient and she has to turn over her shoulder to engage with him (i.e., she is unable to make eye contact). The noise from the running water and the paper dispenser requires them both to raise their voices to communicate. It is an awkward introduction generally, but more so for signed language interpreters and deaf people because of the lack of eye contact and the obscured sight lines caused by the walking-and-talking provider.

The collection of student commentaries can be adapted into a teaching tool. They can be used to teach interpreting students about the practical examples of context. Secondly, they can be used to train educators on the use of this assessment tool - examples of the ways in which each component is represented in the students' reflections.

Any filmed interaction between service professional and service user could function similarly to the SPP videos for use in any setting-specific domain. In addition, specific measures could easily be altered to reflect a different environment. If students are sufficiently primed with other sample filmed interactions (see Dean \& Pollard, 2012, for an example) and become versed in identifying and articulating the components of context, the original exercises (Dean, 2018) and this culminating reflection-in-action activity could be replicated.

\section{Conclusion}

Most of the decisions that practitioners make are influenced by tacit processes; and while it can be the case that those tacit processes are well informed, they can also be misinformed (Argyris \& Schön, 1974; Gladwell, 2005; Kahneman, 2011). Interpreters demonstrate that knowledge - either well informed or misinformed - in their work. If it is true that interpreters' practice and the resulting decisions are a direct function of the immediate context, then professional education should be actively seeking ways to gain proximity to it and improving their understanding and use of that context. Being able to assess and apprehend context in interpreting practice effectively and also the way it drives interpreters' decisions is the 
development of ethical sensitivity, and it should be one of the primary aims in the education of interpreting professionals.

There are many means of accessing the tacit knowledge of practitioners. One of the most effective ways to engage practical knowledge is to create the circumstances through which it is activated. This could be through actual practice settings or by simulating that practice to create a type of cognitive action. Drawing on this cognitive action, practitioners are able to reflect on the context and the hypothetical practice through the theories and frameworks they are taught. Systematically coupling cognitive action with relevant theory and reflection leads knowing-in-action to come to the fore as knowledge-in-action (Schön, 1983). Only when a practitioner's knowing, and their practice knowledge and skills, comes to the fore as knowledge "can it be apprehended, taught, and in some instances targeted for remediation" (Dean, 2015, p. 69).

The course series, Healthcare Practical Interpreting I and II, was designed to teach and ultimately assess the understanding of in situ healthcare interpreting contexts. The final activity (a series of three videos each depicting a unique context) is assessed by using a multicomponent assessment tool. The activities in the courses and the assessment tool are a response to the need for rigour in developing reflective practices. Specifically, this assessment tool seeks to assess the student's rigour as it relates to their understanding of the healthcare interpreting context and of the way context serves to inform their practice. 
Dean, R. K. (2021). Reflection-in-action: Measuring 'context' in medical interpreting, Linguistica

Antverpiensia, New Series: Themes in Translation Studies, 20, 248-266

\section{References}

Angelelli, C. V. (2004). Revisiting the interpreter's role: A study of conference, court, and medical interpreters in Canada, Mexico, and the United States. John Benjamins. https://doi.org/10.10 $\underline{75 / b t l .55}$

Argyris, C., \& Schön, D. A. (1974). Theory in practice: Increasing professional effectiveness. Jossey-Bass.

Barrows, H. S. (1994). Practice-based learning: Problem-based learning applied to medical education. Southern Illinois University School of Medicine.

Bebeau, M. J. (2002). The defining issues test and the four component model: Contributions to professional education. Journal of Moral Education, 31(3), 271-295. https://doi.org/10.1080/ $\underline{0305724022000008115}$

Bindels, E., Verberg, C., Scherpbier, A., Heeneman, S., \& Lombarts, K. (2018). Reflection revisited: How physicians conceptualize and experience reflection in professional practice: A qualitative study. BMC Medical Education, 18(105), 1-10. https://doi.org/10.1186/s12909-018-1218-y

Corsellis, A. (2008). Public service interpreting: The first steps. Palgrave Macmillan. https://doi.org/10. 1057/9780230581951

Davidson, B. (2001). Questions in cross-linguistic medical encounters: The role of the hospital interpreter. Anthropological Quarterly, 74, 170-178. https://doi.org/10.1353/anq.2001.0035

Dean, R. K. (2014). Condemned to repetition?: An analysis of problem-setting and problem-solving in sign language interpreting ethics. Translation \& Interpreting, 6(1), 60-75. https://doi.org/10. 12807/ti.106201.2014.a04

Dean, R. K. (2015). Sign language interpreters' ethical discourse and moral reasoning patterns [Unpublished doctoral dissertation]. Heriot-Watt University.

Dean, R. K. (2018). Over the tipping point: Using the diagnostic discourse of standardized patients to educate medical interpreters. Bakhtiniana. Revista de Estudos do Discurso, 13(3), 171-191. https://doi.org/10.1590/2176-457336495

Dean, R. K., \& Pollard, R. Q. (2001). Application of demand-control theory to sign language interpreting: Implications for stress and interpreter training. Journal of deaf studies and deaf education, 6(1), 1-14. https://doi.org/10.1093/deafed/6.1.1

Dean, R. K., \& Pollard, R. Q. (2005). Consumers and service effectiveness in interpreting work: A practice profession perspective. In M. Marschark, R. Peterson, \& E. A. Winston (Eds.), Sign language interpreting and interpreter education: Directions for research and practice (pp. 259-282). Oxford University Press. https://doi.org/10.1093/acprof/9780195176940.003.001 $\underline{1}$

Dean, R. K., \& Pollard, R. Q. (2009). Effectiveness of observation-supervision training in community mental health interpreting settings. REDIT E-journal on the Didactics of Translation and Interpreting, 3, 1-17.

Dean, R. K., \& Pollard, R. Q. (2011). Context-based ethical reasoning in interpreting: A demand control schema perspective. The Interpreter and Translator Trainer, 5(1), 155-182. https://doi.org/ $10.1080 / 13556509.2011 .10798816$

Dean, R. K., \& Pollard, R. Q. (2012). Beyond "interesting": Using demand control schema to structure experiential learning. In K. Malcolm \& L. Swabey (Eds.), In our hands: Educating healthcare interpreters (pp. 77-104). Gallaudet University Press.

Dean, R. K., \& Pollard, R. Q. (2013). The demand control schema: Interpreting as a practice profession. CreateSpace Independent Publishing Platform.

Farrell, T. S. (2012). Reflecting on reflective practice: (Re)Visiting Dewey and Schön. Tesol Journal, 3(1), 7-16. https://doi.org/10.1002/tesj.10

Gladwell, M. (2005). Blink: The power of thinking without thinking. Little Brown.

Hale, S. B. (2007). Community interpreting. Palgrave Macmillan. https://doi.org/10.1057/9780230593 $\underline{442}$ 
Dean, R. K. (2021). Reflection-in-action: Measuring 'context' in medical interpreting, Linguistica Antverpiensia, New Series: Themes in Translation Studies, 20, 248-266

Hill, A. L. (2004). Ethical analysis in counseling: A case for narrative ethics, moral visions, and virtue ethics. Counseling and Values, 48(2), 131-148. https://doi.org/10.1002/i.2161-007X.2004.tb0 $\underline{0240 . x}$

Howard, C. (2018). Fittingness. Philosophy Compass, 13(11), 1-14. https://doi.org/10.1111/phc3.125 42

Hsieh, E. (2006). Conflicts in how interpreters manage their roles in provider-patient interactions. Social Science \& Medicine, 62(3), 721-730. https://doi.org/10.1016/j.socscimed.2005.06.029

Hsieh, E. (2007). Interpreters as co-diagnosticians: Overlapping roles and services between providers and interpreters. Social Science and Medicine, 64(4), 924-937. https://doi.org/10.1016/j.soc scimed.2006.10.015

Kahneman, D. (2011). Thinking, fast and slow. Penguin Books.

Kinsella, E. A. (2010). The art of reflective practice in health and social care: Reflections on the legacy of Donald Schön. Reflective Practice, 11(4), 565-575. https://doi.org/10.1080/14623943. 2010.506260

Major, G., Napier, J., \& Stubbe, M. (2012). What happens truly, not textbook!: Using authentic interactions in discourse training for healthcare interpreters. In K. Malcolm \& L. Swabey (Eds.), In our hands: Educating healthcare interpreters (pp. 27-53). Gallaudet University Press.

Namy, C. (1978). Reflections on the training of simultaneous interpreters: A metalinguistic approach. In D. Gerver \& H. W. Sinaiko (Eds.), Language interpreting and communication (pp. 25-33). Springer. https://doi.org/10.1007/978-1-4615-9077-4 4

Napier, J. (2004). Interpreting omissions: A new perspective. Interpreting, 6(2), 117-142. https://doi. org/10.1075/intp.6.2.02nap

Pöchhacker, F. (2004) Introducing interpreting studies. Routledge. https://doi.org/10.4324/97802035 $\underline{04802}$

Rest, J. R. (1984). The major components of morality. In W. M. Kurtines \& J. L. Gewirtz (Eds.), Morality, moral behavior, and moral development (pp. 556-629). John Wiley.

Roy, C. B. (2000). Interpreting as a discourse process. Oxford University Press.

Schön, D. A. (1983). The reflective practitioner: How professionals think in action. Basic Books.

Schön, D. A. (1987). Educating the reflective practitioner: Toward a new design for teaching and learning in the professions. Jossey-Bass.

Smith, A. (2014). Think aloud protocols: Viable for teaching, learning, and professional development in interpreting. Translation \& Interpreting, 6(1), 128-143. https://doi.org/10.12807/ti.10620 1.2014.a07

Wadensjö, C. (1998). Interpreting as interaction. Routledge.

Winston, E. A. (2005). Designing a curriculum for American Sign Language/English interpreting educators. In M. Marschark, R. Peterson, \& E. Winston (Eds.), Sign language interpreting and interpreter education: Directions for research and practice (pp. 208-234). Oxford University Press. https://doi.org/10.1093/acprof/9780195176940.003.0009

\footnotetext{
${ }^{i}$ The National Technical Institute for the Deaf is one of nine colleges of the Rochester Institute of Technology, based in Rochester, New York, USA.

ii Some use the term translate to apply only to working with text and interpret to apply only to working with spoken and signed languages, yet the terms are virtually interchangeable. I use translation to mean the final product or decision. Interpretation also can refer to a mental process, as in "My interpretation of what you said is ...". For this reason, I choose to use the term translation to indicate any cross-linguistic decision.
} 
Dean, R. K. (2021). Reflection-in-action: Measuring 'context' in medical interpreting, Linguistica Antverpiensia, New Series: Themes in Translation Studies, 20, 248-266

\footnotetext{
iii Sample questions on worksheets include: What questions that are based on rule-outs or differential diagnosis were asked? What topic areas of the diagnostic interview were covered? What came up in the dialogue either by the patient or the provider that you didn't know? What did you do to find out and where did you look? How did the provider handle medical information and explanation? To what degree was this information or the details explained to the patient? What terms or concepts used by the provider might be a challenge from the fund of information perspective of some patients?
} 